\title{
Childhood overweight and obesity among Kenyan pre-school children: association with maternal and early child nutritional factors
}

\author{
Constance A Gewa*
}

Department of Global \& Community Health, College of Health \& Human Services, George Mason University, 4400 University Drive, MS 5B7, Fairfax, VA 22030, USA

Submitted 11 June 2009: Accepted 23 September 2009: First published online 5 November 2009

\begin{abstract}
Objective: To report on the prevalence of overweight and obesity among preschool children in Kenya and examine the associations between childhood overweight and selected maternal and child-related factors.

Design: Demographic Health Survey data, multistage stratified cluster sampling methodology.

Setting: Rural and urban areas of Kenya.

Subjects: A total of 1495 children between the ages of 3 and 5 years in Kenya. Results: Over $30 \%$ of the children were stunted, approximately $16 \%$ were underweight, $4 \%$ were wasted, approximately $18 \%$ were overweight and $4 \%$ were obese; $8 \%$ were both overweight/obese and stunted. Maternal overweight and obesity, higher levels of maternal education, being a large or very large child at birth, and being stunted were each associated with higher odds of overweight and obesity among Kenyan children. Older children and large household size were each associated with lower odds of overweight and obesity among Kenyan children. Conclusions: The analysis demonstrates the presence of under- and overnutrition among Kenyan pre-school children and the importance of focusing on expanding efforts to prevent and treat malnutrition within this population. It also identifies some of the modifiable factors that can be targeted in these efforts.
\end{abstract}

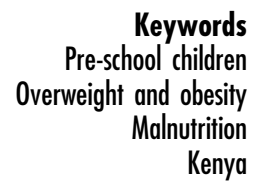

Childhood obesity has become a public health concern in many industrialized and less-developed nations. Overweight and obese children have been shown to have higher risk of becoming overweight/obese adults and to have higher risks of co-morbidities such as high blood pressure, non-insulin-dependent diabetes, hyperlipidaemia, orthopaedic problems and psychological problems, among other negative health effects ${ }^{(1)}$. Countries that have reported on the rates of overweight and obesity among children in Africa have looked at populations within the South African region and North and West African countries ${ }^{(2-6)}$. Information on the presence of overweight/obesity among children in the East African region is relatively lacking. An earlier assessment of Demographic and Health Survey (DHS) data reported that the prevalence of overweight among pre-school children ranged from $1 \%$ in Burundi to $3.5 \%$ in Kenya ${ }^{(7)}$.

Childhood overweight and obesity has been associated with a number of maternal, child- and household-related factors. Maternal and household-related factors have included gestational weight gain, maternal overweight, parental education and household socio-economic status ${ }^{(5,6,8-14)}$. Child-related factors that have shown significant associa- tions with childhood overweight or rate of weight gain include birth weight; feeding practices such as breastfeeding, use of infant formula and time of introduction of other foods; and hours of sleep ${ }^{(6,8-14)}$. Relatively fewer studies have looked at early feeding practices and childhood overweight among populations in Africa. A recent study among pre-school children in rural Nigeria reported a lack of any association between breast-feeding and being overweight or obese ${ }^{(6)}$. Studies that have examined the effect of breast-feeding on childhood overweight in developed nations have reported mixed results, with some showing a protective effect and others indicating a lack of association $^{(8-14)}$. Two recent reviews have concluded that breastfeeding provides a consistent small to moderate level of reduced risk of overweight or obesity among children ${ }^{(15,16)}$. The present analysis reports on the prevalence of overweight and obesity among pre-school children in Kenya and examines the associations between childhood overweight and selected maternal and child-related factors while controlling for demographic and socio-economic factors. The selected maternal and child-related factors include maternal nutritional status as determined by BMI, child's size at birth, childhood stunting and breast-feeding duration. 


\section{Subjects and methods}

The present analysis utilized data collected from the nationwide DHS in Kenya from April to September 2003. The sample for the DHS covered the population residing in households in the country. A representative probability sample of almost 10000 households was selected for the survey ${ }^{(17)}$. This sample was constructed to allow for separate estimates for key indicators for each of the eight provinces in Kenya, as well as for urban and rural areas separately. The DHS utilizes a multistage stratified cluster sampling methodology in which samples of households within clusters (enumeration areas) are selected. Urban areas were oversampled and the data have been weighted to cater for the different sample proportions. A total of 400 clusters - 129 urban and 271 rural - were selected from the master frame in the first stage. Households were then systematically selected within each cluster and household residents were eligible to participate in the survey ${ }^{(17)}$. Mothers were the main study respondents, with weights and heights/lengths measured among mothers and all children below 5 years of age. The Kenya DHS experienced high response rates of $96 \%$ among the systematically selected households and 94\% among eligible women of reproductive age. Because breast-feeding duration was one of the covariates in the present study, a decision was made to restrict the analysis to children aged 3-5 years, a time when most (97\%) of them had stopped breast-feeding. The DHS protocol was approved by ORC Macro's Institutional Review Board.

\section{Weight and length/beight measurements}

Weights and heights among all children below 5 years of age and women of reproductive age within each of the participating households were measured. Weight was measured to the nearest $0.5 \mathrm{~kg}$ using a lightweight, bathroom-type scales with a digital screen designed and manufactured under the authority of $\mathrm{UNICEF}^{(17)}$. Each subject was measured wearing light clothing without shoes or stockings. Length and height were measured to the nearest $0 \cdot 1 \mathrm{~cm}$ using a calibrated height board/flexible tape. The measuring boards were specially produced by Shorr Productions (Olney, MD, USA) for use in survey settings. The WHO 2006 growth reference standards, which use the WHO Multicentre Growth Reference Study population, were used to transform children's weight and height measurements into sex- and age-specific $Z$-scores: height-for-age $Z$-score (HAZ), weight-for-age $Z$-score (WAZ), weight-for-height $Z$-score (WHZ) and BMI-for-age $Z$-score $(\mathrm{BAZ})^{(18)}$. Weight-for-height $Z$-score was calculated for those with heights of 65 to $120 \mathrm{~cm}$. Stunting was defined as HAZ below $-2 \mathrm{sD}$, underweight was defined as WAZ below $-2 \mathrm{SD}$, wasting was defined as WHZ below $-2 \mathrm{SD}$, overweight was defined as $+1 \mathrm{SD}<\mathrm{BAZ} \leq+2 \mathrm{SD}$, obese was defined as $\mathrm{BAZ}>+2 \mathrm{SD}$, and overweight or obese was defined as BAZ $>+1 \mathrm{SD}$ among children. $+1 \mathrm{SD}$ is equivalent to the 85 th percentile while $+2 \mathrm{SD}$ is equivalent to the 97 th percentile ${ }^{(18)}$.

Maternal BMI was computed as weight in kilograms divided by the square of height in metres. BMI cut-offs were based on the recommended international cut-offs as follows: underweight was defined as BMI $<18.5 \mathrm{~kg} / \mathrm{m}^{2}$, normal body weight was defined as BMI $=18 \cdot 5-24 \cdot 9 \mathrm{~kg} /$ $\mathrm{m}^{2}$, overweight was defined as $\mathrm{BMI}=25 \cdot 0-29 \cdot 9 \mathrm{~kg} / \mathrm{m}^{2}$ and obese was defined as $\mathrm{BMI} \geq 30 \cdot 0 \mathrm{~kg} / \mathrm{m}^{2}$.

\section{Child's birth size}

Child's weight at birth was either recorded from the child health cards or self-reported by the mother. In addition, mothers were asked to indicate the child's size at birth from a range of values: 'very small', 'smaller than average', 'average', 'larger than average' and 'very large'. Over 53\% of the children had missing information on their birth weights, and so the reported child's size at birth was used in the analysis. There was a significant positive association between child's birth weight and the subjective measure child's size $(r=0 \cdot 60, P<0 \cdot 0001)$ for records with both birth weight and size at birth. Information was also collected on whether the child was a twin.

\section{Breast-feeding practices}

Mothers were asked if the children were breast-feeding at the time of the survey and breast-feeding duration. The following breast-feeding duration categories were created: $\leq 12$ months, 12-18 months, 18-24 months and $>24$ months. Breast-feeding duration, as used here, represents any breast-feeding and not exclusive breast-feeding.

\section{Maternal education}

Information was collected on the highest level of education attained by the mothers. Education levels included no school/pre-school, primary school, secondary school and post-secondary.

\section{Wealtb index}

Information on household assets was collected and included the following: source of water, type of toilet facilities, materials used for the floor and roof of the house, type of fuel and ownership of various durable goods (radio, television, refrigerator, bicycle, motorcycle, car, telephone and bed net). A socio-economic index was constructed as an indicator of the level of wealth that is consistent with expenditure and income measures. Each asset was assigned a factor score generated through principal components analysis, and the resulting asset scores were standardized in relation to a normal distribution with a mean of zero and standard deviation of one. Each household was then assigned a score for each asset and the scores were summed for each household. The sample was then divided into quintiles from one (lowest) to five (highest) ${ }^{(17)}$. 


\section{Housebold size and participant's age and sex}

Number of household members was collected as part of the survey. For the present analysis, de facto household members were used in defining household size. Data were collected on age, sex, education, and relationship to the head of the household for each of the household members. Child's age was recorded in months while mother's age was recorded in years.

\section{Statistical analysis}

Complete sets of weight and height measurements were available for $92 \%$ (1747 out of 1906) of all the pre-school children (3-5 years old) included in the survey. Out of the remaining 1747, 206 were excluded because their mothers were pregnant at the time of the study. A further forty-six children were identified as twins and excluded from the analyses. Fifty households had two children between the ages of 3 and 5 years and only the youngest child from each of these households was included in the analyses, which makes up 86\% (1495 out of 1747) of all children aged 3-5 years who were in the DHS sample. The SAS statistical software package version 9.1 (SAS Institute, Cary, NC, USA) was used for data analysis. Survey analysis procedures were appropriate for complex survey study designs and were utilized to help estimate sampling errors. The SAS procedures SURVEYFREQ, SURVEYMEANS and SURVEYLOGISTIC were used to estimate means, percentages and odds ratios. Logistic regression analysis was used to assess the odds of being overweight or obese (BAZ $>+1 \mathrm{sD})$ referred to hereafter as 'overweight'. Bivariate logistic regression was used to assess the association between each of the selected demographic and socio-economic factors and child overweight. Factors that showed a significant association with being overweight were included in the basic multivariate logistic regression that assessed the association between child overweight status and socio-economic and demographic factors. Child's sex was included in the multivariate analysis. The associations between selected child and maternal factors and child overweight status were each assessed separately and within multivariate regression models.

\section{Results}

Children's ages ranged from 36 to 59 months with a mean of 46.57 (SD 0 20) months. No significant differences by gender were noted in the children's ages. Overall, 36\%, 16\% and $4 \%$ of the children were stunted, underweight and wasted (Table 1). Wasting prevalence was significantly higher among male children (4.94 (SD 1.20)\% v. 2.92 (SD 0.62)\%, $P=0 \cdot 041$. Eighteen per cent of the pre-school children were overweight, while $4 \%$ were obese. About $8 \%$ were both stunted and overweight. The prevalences of overweight and obesity decreased with age: overweight prevalence from $23 \cdot 80 \%$ among ages $36-41$ months to $13 \cdot 14 \%$ among ages 55-59 months while obesity prevalence ranged from $3 \cdot 13 \%$ to $9 \cdot 17 \%$ among the different age groups (Fig. 1).

A higher percentage of the overweight/obese children were larger at birth $(P<0 \cdot 01 ;$ Table 2$)$. They were also younger $(44.38$ (SD $0 \cdot 20)$ months $v$. 47.04 (SD 0.21) months, $P<0 \cdot 0001)$ and had shorter mean breast-feeding duration (18.73 (SD 0.50) months $v$. 20.01 (SD 0.24) months, $P=0 \cdot 021$ ). The percentage of children who were never breast-fed or who were still breast-feeding at the time of the study did not differ by child overweight status. Compared with children who were not overweight/ obese, a significantly higher percentage of overweight/ obese children lived in the urban areas and vice versa for rural areas $(P<0 \cdot 01)$. Overweight/obese children also had a higher percentage of mothers who were overweight and obese $(P<0 \cdot 001$; Table 3$)$.

\section{Regression analyses}

Socio-economic and demographic factors and overweight There were significant associations between child overweight status and each of the covariates: child's age and maternal education level $(P<0 \cdot 05)$. Older children had significantly lower odds being overweight. Compared with mothers who had no or pre-school level of education, maternal attainment of primary school, secondary school and post-secondary levels of education were each associated with an increase in odds of the child being overweight. The basic model accounted for $5 \cdot 8 \%$ of the overweight variance (Table 4).

Table 1 Prevalence of malnutrition among pre-school children, all and by sex: Kenyan Demographic and Health Survey, April-September 2003

\begin{tabular}{|c|c|c|c|c|c|c|}
\hline \multirow[b]{2}{*}{ Nutritional status } & \multicolumn{2}{|c|}{ All $(n$ 1443) } & \multicolumn{2}{|c|}{ Males $(n 740)$} & \multicolumn{2}{|c|}{ Females ( $n$ 703) } \\
\hline & $\%$ & $95 \% \mathrm{Cl}$ & $\%$ & $95 \% \mathrm{Cl}$ & $\%$ & $95 \% \mathrm{Cl}$ \\
\hline Stunted & $35 \cdot 79$ & $35 \cdot 63,38 \cdot 94$ & 39.99 & $34.03,41.94$ & $33 \cdot 49$ & $28.95,38.02$ \\
\hline Underweight & $16 \cdot 42$ & $14 \cdot 09,18 \cdot 74$ & $18 \cdot 26$ & $14 \cdot 87,21 \cdot 65$ & $14 \cdot 50$ & $11 \cdot 54,17 \cdot 47$ \\
\hline Wasted $^{*}$ & 3.95 & $2 \cdot 41,5 \cdot 49$ & 4.94 & $2 \cdot 57,7 \cdot 31$ & 2.92 & $1 \cdot 69,4 \cdot 15$ \\
\hline Overweight/obese & $17 \cdot 78$ & $15 \cdot 96,19 \cdot 60$ & $18 \cdot 32$ & $15 \cdot 74,20 \cdot 91$ & $17 \cdot 21$ & $14 \cdot 41,20 \cdot 00$ \\
\hline Obese & 3.79 & $2 \cdot 78,4 \cdot 79$ & 4.47 & $2 \cdot 98,5 \cdot 97$ & 3.07 & $1 \cdot 88,4 \cdot 25$ \\
\hline Stunted \& overweight/obese & $8 \cdot 10$ & $6 \cdot 55,9 \cdot 64$ & 8.99 & $7 \cdot 01,10 \cdot 96$ & $7 \cdot 17$ & $4 \cdot 97,9 \cdot 36$ \\
\hline
\end{tabular}

Stunted, height/length-for-age Z-score $<-2$; underweight, weight-for-age $Z$-score $<-2$; wasted, weight-for-height $Z$-score $<-2$; overweight/obese, BMI-forage $Z$-score $>+2 \mathrm{sD}$; obese, BMl-for-age $Z$-score $>+1 \mathrm{sD}$; stunted \& overweight/obese: height/length-for-age $Z$-score $<-2$ and BMI-for-age $Z$-score $>+2$ sD. Percentage values were significantly different between the sexes: ${ }^{*} P<0.05$. 


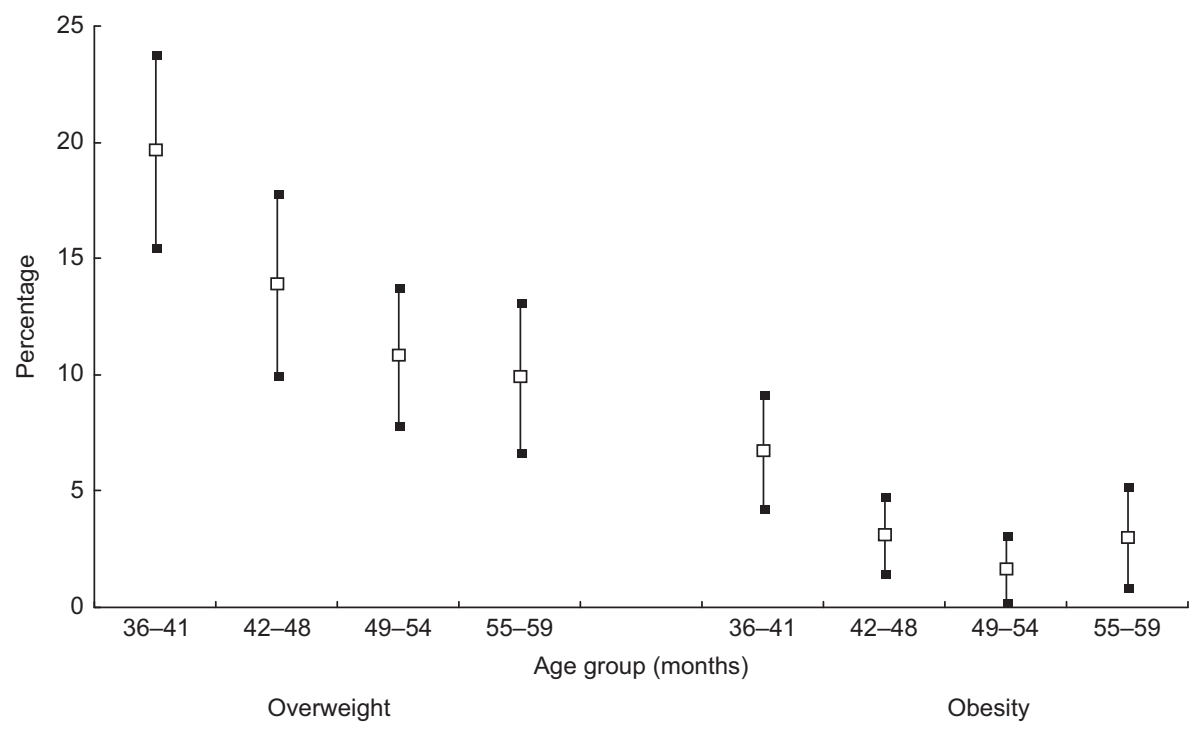

Fig. 1 Prevalence of overweight and obesity in pre-school children by age group: Kenyan Demographic and Health Survey, April-September 2003. Values are means $(\square)$ with their $95 \%$ confidence limits

Table 2 Comparison of child factors and breast-feeding rates by children's overweight/obesity status: Kenyan Demographic and Health Survey, April-September 2003

\begin{tabular}{|c|c|c|c|c|c|c|}
\hline & \multicolumn{2}{|c|}{ All $(n$ 1443) } & \multicolumn{2}{|c|}{ Overweight/obese ( $n$ 255) } & \multicolumn{2}{|c|}{ Not overweight/obese ( $n$ 1188) } \\
\hline & $\%$ & SE & $\%$ & SE & $\%$ & SE \\
\hline \multicolumn{7}{|l|}{ Size at birth** } \\
\hline Smaller/very small & $14 \cdot 44$ & 0.86 & $10 \cdot 05$ & $2 \cdot 14$ & $15 \cdot 38$ & $1 \cdot 01$ \\
\hline Average & $59 \cdot 85$ & $1 \cdot 39$ & $54 \cdot 46$ & $3 \cdot 20$ & $61 \cdot 01$ & $1 \cdot 62$ \\
\hline Larger/very large & $25 \cdot 71$ & $1 \cdot 33$ & 35.49 & $2 \cdot 89$ & $23 \cdot 60$ & $1 \cdot 49$ \\
\hline \multicolumn{7}{|l|}{ Breast-feeding status } \\
\hline Never breast-fed & $1 \cdot 29$ & 0.30 & $0 \cdot 71$ & 0.43 & $1 \cdot 41$ & 0.35 \\
\hline Currently breast-feeding & 2.04 & 0.36 & $2 \cdot 38$ & 1.05 & 1.97 & $0 \cdot 42$ \\
\hline \multicolumn{7}{|l|}{ Breast-feeding duration } \\
\hline$<12$ months & $12 \cdot 70$ & 0.86 & $16 \cdot 72$ & $2 \cdot 29$ & $11 \cdot 83$ & 0.94 \\
\hline $12-18$ months & $35 \cdot 49$ & $1 \cdot 34$ & $37 \cdot 60$ & $2 \cdot 86$ & $35 \cdot 04$ & $1 \cdot 43$ \\
\hline 19-24 months & $34 \cdot 80$ & $1 \cdot 21$ & 31.97 & 3.02 & $35 \cdot 41$ & $1 \cdot 40$ \\
\hline$>24$ months & $17 \cdot 01$ & $1 \cdot 12$ & $13 \cdot 71$ & $2 \cdot 38$ & $17 \cdot 72$ & $1 \cdot 27$ \\
\hline
\end{tabular}

Overweight/obese, $\mathrm{BMI}>85$ th percentile; not overweight/obese, $\mathrm{BMI} \leq 85$ th percentile.

Percentage values were significantly different between overweight status: ${ }^{\star *} P<0 \cdot 01$.

Maternal nutritional status and childhood overweight There was a significant association between maternal nutritional status and childhood overweight status $(P<0 \cdot 05)$. This association was maintained even after adjusting for the socio-economic and demographic factors. Maternal underweight status was associated with a $53 \%$ reduction in odds of the child being overweight, while maternal overweight and obesity were respectively associated with $83 \%$ and $112 \%$ increases in odds of child overweight (Table 5). Including maternal nutritional status increased the variance explained to $8 \cdot 5 \%$ compared with the basic model.

\section{Size at birth and childhood overweight}

There was a positive association between size at birth and childhood overweight that was maintained after adjusting for socio-economic and demographic factors $(P<0 \cdot 05)$. Compared with children of average size at birth, those who were reported to have been larger than average or very large at birth had a $68 \%$ increase in odds of being overweight (Table 5). Including size at birth increased the variance explained to $7 \cdot 7 \%$ compared with the basic model.

\section{Stunting status and childhood overweight}

There was a positive association between stunting and childhood overweight $(P<0 \cdot 05)$. After adjusting for socioeconomic and demographic factors, children who were stunted had a $70 \%$ increase in odds of being overweight compared with those who were not stunted (Table 5). Including child stunting status increased the variance explained to $7 \cdot 2 \%$ compared with the basic model. 
Table 3 Comparison of household and maternal factors by children's overweight/obesity status: Kenyan Demographic and Health Survey, April-September 2003

\begin{tabular}{|c|c|c|c|c|c|c|}
\hline & \multicolumn{2}{|c|}{ All $(n$ 1443) } & \multicolumn{2}{|c|}{ Overweight/obese (n 255) } & \multicolumn{2}{|c|}{ Not overweight/obese ( $n 1188$} \\
\hline & $\%$ & $\mathrm{SE}$ & $\%$ & $\mathrm{SE}$ & $\%$ & SE \\
\hline \multicolumn{7}{|c|}{ Maternal nutritional status ${ }^{\star \star \star}$} \\
\hline Underweight & $12 \cdot 50$ & $1 \cdot 02$ & $6 \cdot 15$ & $1 \cdot 89$ & $13 \cdot 87$ & $1 \cdot 17$ \\
\hline Normal BMI & $66 \cdot 91$ & $1 \cdot 30$ & $63 \cdot 89$ & $3 \cdot 45$ & $67 \cdot 59$ & 1.51 \\
\hline Overweight & $14 \cdot 61$ & 0.93 & $21 \cdot 23$ & $2 \cdot 02$ & $13 \cdot 18$ & 0.99 \\
\hline Obese & $5 \cdot 98$ & $0 \cdot 71$ & $8 \cdot 73$ & $1 \cdot 76$ & $5 \cdot 38$ & 0.78 \\
\hline \multicolumn{7}{|l|}{ Maternal education level } \\
\hline None/pre-school & $13 \cdot 63$ & $1 \cdot 49$ & $8 \cdot 75$ & $1 \cdot 84$ & $14 \cdot 69$ & $1 \cdot 70$ \\
\hline Primary school & $62 \cdot 74$ & $1 \cdot 77$ & $64 \cdot 38$ & $3 \cdot 21$ & $62 \cdot 39$ & 1.93 \\
\hline Secondary school & $20 \cdot 26$ & $1 \cdot 41$ & 21.98 & $2 \cdot 81$ & $19 \cdot 89$ & 1.56 \\
\hline Post-secondary school & 3.34 & 0.55 & $4 \cdot 88$ & $1 \cdot 37$ & 3.02 & 0.58 \\
\hline \multicolumn{7}{|l|}{ Residence location** } \\
\hline Urban & $16 \cdot 09$ & $1 \cdot 19$ & $21 \cdot 83$ & $2 \cdot 83$ & $14 \cdot 85$ & $1 \cdot 15$ \\
\hline Rural & 83.91 & $1 \cdot 19$ & $78 \cdot 17$ & $2 \cdot 83$ & $85 \cdot 15$ & $1 \cdot 15$ \\
\hline Household size* & $6 \cdot 19$ & 0.08 & $5 \cdot 90$ & $0 \cdot 14$ & $6 \cdot 25$ & $0 \cdot 10$ \\
\hline \multicolumn{7}{|l|}{ Wealth index } \\
\hline First quintile & $24 \cdot 40$ & $1 \cdot 71$ & $23 \cdot 88$ & $2 \cdot 99$ & $24 \cdot 51$ & $1 \cdot 86$ \\
\hline Second quintile & $22 \cdot 32$ & $1 \cdot 35$ & $19 \cdot 67$ & $2 \cdot 53$ & $22 \cdot 89$ & 1.50 \\
\hline Third quintile & $19 \cdot 90$ & $1 \cdot 28$ & $17 \cdot 55$ & $2 \cdot 54$ & $20 \cdot 41$ & $1 \cdot 30$ \\
\hline Fourth quintile & $17 \cdot 55$ & $1 \cdot 38$ & $16 \cdot 82$ & $2 \cdot 76$ & $17 \cdot 71$ & 1.52 \\
\hline Fifth quintile & $15 \cdot 83$ & $1 \cdot 47$ & $22 \cdot 08$ & $2 \cdot 72$ & $14 \cdot 48$ & $1 \cdot 52$ \\
\hline
\end{tabular}

Overweight/obese, $\mathrm{BMI}>85$ th percentile; not overweight/obese, $\mathrm{BMI} \leq 85$ th percentile.

Percentage values were significantly different between overweight status: ${ }^{\star} P<0.05,{ }^{\star \star} P<0.01,{ }^{\star * *} P<0.001$.

Table 4 Relationship between childhood overweight/obesity and socio-economic and demographic factors: Kenyan Demographic and Health Survey, April-September 2003

\begin{tabular}{|c|c|c|}
\hline Factor & OR & $95 \% \mathrm{Cl}$ \\
\hline Child's age (months) & $0.95^{\star}$ & $0.92,0.97$ \\
\hline \multicolumn{3}{|l|}{ Child's sex } \\
\hline Male (ref) & $1 \cdot 00$ & \\
\hline Female & 0.93 & $0 \cdot 71,1 \cdot 24$ \\
\hline \multicolumn{3}{|l|}{ Maternal education level } \\
\hline None/pre-school (ref) & 1.00 & \\
\hline Primary school & $1 \cdot 79^{*}$ & $1 \cdot 09,2 \cdot 93$ \\
\hline Secondary school & $1 \cdot 91^{*}$ & $1.05,3.45$ \\
\hline Post-secondary school & $2 \cdot 56$ & $1 \cdot 09,6 \cdot 02$ \\
\hline \multicolumn{3}{|l|}{ Residence location } \\
\hline Rural (ref) & $1 \cdot 00$ & \\
\hline Urban & $1 \cdot 31$ & $0 \cdot 76,2 \cdot 26$ \\
\hline Household size & 0.96 & $0.90,1.02$ \\
\hline \multicolumn{3}{|l|}{ Wealth index } \\
\hline First quintile (ref) & $1 \cdot 00$ & \\
\hline Second quintile & $0 \cdot 78$ & $0.50,1 \cdot 22$ \\
\hline Third quintile & $0 \cdot 78$ & $0.51,1 \cdot 21$ \\
\hline Fourth quintile & $0 \cdot 80$ & $0.49,1.32$ \\
\hline Fifth quintile & 0.96 & $0.50,1 \cdot 85$ \\
\hline
\end{tabular}

ref, referent category.

OR values were statistically significant: ${ }^{\star} P<0.05$.

Breast-feeding duration and childhood overweight

There was an inverse dose-response relationship between breast-feeding duration and child overweight/ obesity. Longer breast-feeding duration ( $>18$ months) was significantly associated with lower risks of childhood overweight/obesity $(P<0 \cdot 05)$. The dose-response association was maintained after controlling for other variables; however, significant association was maintained only for breast-feeding duration above 24 months. Compared with children who had breast-fed for less than
12 months, children who had breast-fed for more than 24 months had a $45 \%$ decrease in odds of being overweight (Table 5). Including breast-feeding duration increased the variance explained to $6.5 \%$.

The final regression model that included both the original socio-economic and demographic variables and the selected maternal and child factors explained $12 \cdot 8 \%$ of the variance in overweight. Although not shown, there were significant associations between child overweight status and each of the following socio-economic and demographic covariates: child's age, maternal education level and household size $(P<0 \cdot 05)$. Maternal overweight, child's size at birth, child stunting status and breastfeeding duration were each significantly associated with child overweight or obesity $(P<0.05$; Table 5$)$. Being 1 month older was associated with a $5 \%$ reduction in odds of being overweight or obese. Increasing household membership by one was associated with a $7 \%$ reduction in odds of being overweight or obese. Compared with mothers who had no or pre-school level of education, maternal attainment of primary and secondary school level of education was respectively associated with $72 \%$ and $91 \%$ increased odds of the child being overweight. Maternal underweight was associated with a $53 \%$ reduction in the odds of child overweight, while maternal overweight and obesity were respectively associated with $83 \%$ and $112 \%$ increases in the odds of child overweight. Compared with children of average size at birth, children who were larger than average or very large at birth had a $69 \%$ increase in odds of being overweight. Compared with non-stunted children, stunted children had a $93 \%$ increase in odds of being overweight. Children who had 
Table 5 Relationship between childhood overweight/obesity and maternal and child factors: Kenyan Demographic and Health Survey, April-September 2003

\begin{tabular}{|c|c|c|c|c|c|c|}
\hline & \multicolumn{2}{|c|}{ Model At } & \multicolumn{2}{|c|}{ Model Bł } & \multicolumn{2}{|c|}{ Model C§ } \\
\hline & OR & $95 \% \mathrm{Cl}$ & OR & $95 \% \mathrm{Cl}$ & OR & $95 \% \mathrm{Cl}$ \\
\hline \multicolumn{7}{|c|}{ Maternal nutritional status } \\
\hline Normal BMI (ref) & $1 \cdot 00$ & & $1 \cdot 00$ & & 1.00 & \\
\hline Underweight & $0 \cdot 47^{\star}$ & $0.24,0.93$ & $0.49^{*}$ & $0.24,0.99$ & $0.47^{*}$ & $0.23,0.98$ \\
\hline Overweight & $1 \cdot 70^{*}$ & $1 \cdot 16,2 \cdot 50$ & $1 \cdot 75^{\star}$ & $1 \cdot 16,2 \cdot 63$ & $1 \cdot 83^{*}$ & $1 \cdot 20,2 \cdot 81$ \\
\hline Obese & $1 \cdot 71$ & $0.98,2.99$ & $1 \cdot 84^{*}$ & $1 \cdot 01,3.35$ & $2 \cdot 12^{*}$ & $1 \cdot 11,4.07$ \\
\hline \multicolumn{7}{|l|}{ Size at birth } \\
\hline Average (ref) & $1 \cdot 00$ & & $1 \cdot 00$ & & $1 \cdot 00$ & \\
\hline Smaller/very small & 0.73 & $0.43,1.25$ & $0 \cdot 70$ & $0.43,1.20$ & 0.64 & $0 \cdot 37,1 \cdot 12$ \\
\hline Larger/very large & $1 \cdot 68^{*}$ & $1 \cdot 23,2 \cdot 31$ & $1 \cdot 68^{*}$ & $1 \cdot 19,2 \cdot 24$ & $1 \cdot 69^{*}$ & $1 \cdot 21,2 \cdot 37$ \\
\hline \multicolumn{7}{|l|}{ Child stunted } \\
\hline No (ref) & $1 \cdot 00$ & & $1 \cdot 00$ & & 1.00 & \\
\hline Yes & $1 \cdot 65^{\star}$ & $1 \cdot 23,2 \cdot 21$ & $1 \cdot 70^{*}$ & $1 \cdot 24,2 \cdot 33$ & $1.93^{*}$ & $1 \cdot 37,2 \cdot 7 \varepsilon$ \\
\hline \multicolumn{7}{|l|}{ Breast-feeding duration } \\
\hline$<12$ months (ref) & 1.00 & & $1 \cdot 00$ & & $1 \cdot 00$ & \\
\hline $12-18$ months & 0.76 & $0.51,1.12$ & 0.84 & $0.56,1.27$ & $0 \cdot 80$ & $0.53,1.21$ \\
\hline 19-24 months & $0.64^{*}$ & $0.41,0.99$ & 0.72 & $0 \cdot 46,1 \cdot 11$ & 0.67 & $0.43,1.04$ \\
\hline$>24$ months & $0.55^{\star}$ & $0.33,0.92$ & $0.57^{\star}$ & $0.34,0.97$ & $0.55^{*}$ & $0.32,0.94$ \\
\hline
\end{tabular}

ref, referent category.

OR values were statistically significant: ${ }^{\star} P<0.05$.

tCrude associations.

¥Separate regression models each adjusting for socio-economic and demographic factors, i.e. child’s sex, child’s age, household wealth index, household size, residence (rural $v$. urban) and maternal education.

$\S$ Final model including socio-economic and demographic factors, maternal BMI, child's size at birth, child's stunting status and breast-feeding duration.

breast-fed for more than 24 months had a $45 \%$ decrease in odds of being overweight when compared with those who had breast-fed for less than 12 months.

\section{Discussion}

The current analysis demonstrates the presence of underand overnutrition among Kenyan under-5s. Over $30 \%$ of the children were stunted, approximately $16 \%$ were underweight, $4 \%$ were wasted, approximately $18 \%$ were overweight and $4 \%$ were obese. Although the prevalence of stunting, underweight and wasting has declined over the years ${ }^{(17)}$, the underweight and stunting prevalences found here indicate the presence of a medium- and highlevel public health problem, respectively ${ }^{(19)}$. Moreover, overweight and obesity is on the rise and the prevalence found here is higher than that reported in a previous DHS study $^{(7)}$. A recent study that assessed nutritional status among school-aged (5-17 years old) children in rural western Kenya reported that $8-10 \%$ of 5- to 6-year-olds were overweight ${ }^{(20)}$. In the present analysis, the prevalence of overweight/obesity started off at approximately $13 \%$ among 55-59-month-olds. Eight per cent of the children were both overweight/obese and stunted.

Maternal nutritional status was significantly associated with overweight and obesity among Kenyan pre-school children. While maternal underweight was associated with lower odds of the child being overweight, maternal overweight and obesity were both associated with increased odds of the child being overweight or obese. The significant association between maternal nutritional status and child overweight or obesity could be a result of genetic factors leading to familial predisposition to overweight. Individuals vary in the way their bodies respond to environmental interventions such as dietary fat, with $30-50 \%$ of the variance in adiposity within a population being attributed to genetic variability ${ }^{(21)}$. Some studies have shown high dietary fat intake to be a significant predictor for development of obesity among women only when there was familial predisposition ${ }^{(22)}$. Mothers and children also share environments that may predispose them to increased risks for the development of overweight and obesity. Previous research has shown that children are more likely to consume high levels of total fat, saturated fat and cholesterol if their parents consume high levels of these nutrients ${ }^{(23)}$. The association between parental and children's dietary practices was shown to be even stronger when considering mother's and children's intakes than when comparing father's and children's intakes, suggesting that maternal dietary practices may have a stronger influence on children's nutrient intake ${ }^{(23)}$. Children of obese mothers have been shown to have higher levels of dietary fat intake ${ }^{(24)}$. In addition, higher fat intake levels have been shown to be significantly associated with children's body fat mass ${ }^{(24)}$. Mothers who are undernourished may be relying on very limited resources with limited food access. Overweight mothers also tend not to practise breast-feeding, which leads to their children not benefiting from any protective effect that breast-feeding may offer ${ }^{(10)}$.

Overall breast-feeding duration averaged 20 months for the children in the present study, with only $1.3 \%$ not breast-fed at all. The unadjusted odds ratio indicated 
a protective effect for breast-feeding durations beyond 18 months; however, after controlling for other variables, this effect was maintained only for breast-feeding duration beyond 24 months. The effect of breast-feeding on childhood overweight may be a result of different mechanisms including learned self-control, the biological properties of breast milk possibly inhibiting adipocyte differentiation $^{(16)}$, or the presence of environmental factors $^{(15)}$. Studies have shown that mothers who practise breast-feeding exert lower levels of control over the amount of milk the infants can consume, thus allowing infants to learn to control their intake and to be more responsive to satiety and hunger cues even during the subsequent years ${ }^{(15,25)}$. The current analysis shows that after adjusting for other factors (socio-economic, demographic, maternal and child factors), breast-feeding for at least 24 months seems to protect against childhood obesity among Kenyan pre-school children.

It is important to note that even though $98 \%$ of the mothers reported initiating breast-feeding, the prevalence of childhood overweight/obesity lies at $18 \%$. It is possible that, for this group of children, any protective effect that may be provided by breast-feeding may have been eroded by the early introduction of other foods and consequent reduction in breast-feeding intensity. Concurrent use of infant formula has been shown to reduce the extent of the protective effect that breast-feeding may have on childhood overweight ${ }^{(11)}$. Kenyan children are introduced to other types of milk and foods at very early ages, with $15 \cdot 0 \%$ and $15 \cdot 5 \%$ of children less than 2 months old having been given other types of milk and complementary foods, respectively ${ }^{(17)}$. The most common types of other foods include whole cow's milk, porridge, potatoes, bananas and rice, which tend to have higher energy density compared with breast milk. In Kenya, longer breast-feeding duration has been noted among mothers in rural areas, mothers with no education compared with those having secondary education, and mothers in households with lower levels of wealth ${ }^{(17)}$, an indication of possible association with other cultural and socio-economic factors.

Children who were considered larger at birth had higher odds of being overweight. These findings are similar to studies that have reported a positive association between birth weight and overweight and obesity in child$\operatorname{hood}^{(8,26-28)}$. Eight per cent of the children were both overweight and stunted and the presence of stunting was associated with significantly higher odds of being overweight. Stunting and overweight have been previously reported to coexist among children and adolescents in Africa ${ }^{(5,29,30)}$. Possible explanations may include environmental factors such as lower levels of physical activity ${ }^{(29)}$. The other biological explanation could lie in the manner in which fat is oxidized in the presence of stunting. Stunted children were shown to have significantly lower levels of fat oxidation, resulting in higher amounts of fat being stored ${ }^{(31)}$.
Maternal attainment of primary and secondary school level of education was associated with higher odds of childhood overweight. Higher maternal education is often associated with maternal employment and higher household income. Higher income may lead to increased access to more 'higher status' foods, which are often higher in sugar and fat content levels ${ }^{(29)}$. Higher maternal education level could also indicate that mothers are spending more time outside the home, leaving little time to care for the children ${ }^{(5,32)}$. Larger households were associated with lower odds of childhood overweight. An increase in household membership has previously been associated with both stunting and overweight among young children ${ }^{(33)}$. This association could be a result of a reduction in the overall amounts of foods and type of care available to each household member as the household size increases.

While the presence of overweight and obesity among Kenyan adults has been noted, very little has been reported on childhood overweight in the country ${ }^{(34,35)}$. The current analysis documents the presence of overweight and obesity among Kenyan children and explains $12 \cdot 81 \%$ of the variance in overweight among Kenyan preschool children. The strengths of study lie in its use of a nationwide sample, its assessment of important child and maternal factors, and in accounting for certain social and demographic factors that have been shown to be associated with childhood overweight in different populations. However, the analysis does suffer some limitations including a lack of information on dietary practices such as duration of exclusive breast-feeding and time of introduction of other foods, which may have provided further understanding of childhood overweight and obesity among these children. Higher energy intake among formula-fed and mixed-fed infants at 4 months of age has been associated with higher BMI levels at 3 or 5 years of age ${ }^{(36)}$, while concurrent use of infant formula has been shown to reduce the extent of the protective effect that breast-feeding may have on childhood overweight $^{(11)}$. Kenyan children are introduced to other types of milk and foods at very early ages. Information on dietary intake at the time of the survey would have been useful as well. Another limitation may lie in the fact that a subjective indicator of size at birth was used; however, there was a significant positive correlation between the subjective measure and birth weight. Additional information such as length of gestation and gestational weight gain may have helped provide further understanding of childhood overweight in Kenya.

Overweight and obesity is on the rise among Kenyan children. This increase is occurring at a time when the country still suffers high levels of childhood undernutrition especially stunting. While it may be difficult to modify maternal education levels, maternal and child nutritional status and nutrition-related factors are modifiable and can be targeted through public health interventions to a certain 
degree $^{(37)}$. Childhood overweight has been associated with negative health outcomes ${ }^{(1)}$. As the Kenyan Government continues in its fight towards reducing undernutrition, it should expand or modify these efforts to include ways that may help prevent and reduce prevalence of overweight within the population.

\section{Acknowledgements}

No specific funding was obtained for the study and there are no conflicts of interest. The author acknowledges ORC Macro for making the DHS data available, Dr Panagiota Kitsantas for guidance on statistical analysis and Lauren Savaglio for editorial assistance.

\section{References}

1. Deckelbaum RJ \& Williams CL (2001) Childhood obesity: the health issue. Obes Res 9, Suppl. 4, 239S-243S.

2. Monyeki KD, van Lenthe FJ \& Steyn NP (1999) Obesity: does it occur in African children in a rural community in South Africa? Int J Epidemiol 28, 287-292.

3. Monyeki KD, Monyeki MA, Brits SJ et al. (2008) Development and tracking of body mass index from preschool age into adolescence in rural South African children: Ellisras longitudinal growth and health study. J Health Popul Nutr 26, 405-417

4. Mokhtar N, Elati J, Chabir R et al. (2001) Diet culture and obesity in North Africa. $J$ Nutr 131, issue 3, 887S-892S.

5. Mamabolo RL, Alberts M, Steyn NP et al. (2005) Prevalence and determinants of stunting and overweight in 3-year-old black South African children residing in the central region on Limpopo province, South Africa. Public Health Nutr 8 , 501-508.

6. Senbanjo IO \& Adejuyigbe EA (2007) Prevalence of overweight and obesity in Nigerian preschool children. Nutr Health 18, 391-399.

7. de Onis M \& Blossner M (2000) Prevalence and trends of overweight among preschool children in developing countries. Am J Clin Nutr 72, 1032-1039.

8. Zive MM, McKay H, Frank-Spohrer GC et al. (1992) Infantfeeding practices and adiposity in 4-y old Anglo- and Mexican-Americans. Am J Clin Nutr 55, 1104-1108.

9. von Kries R, Koletzko B, Sauerwald T et al. (1999) Breast feeding and obesity: cross sectional study. BMJ 319, 147-150.

10. Hediger ML, Overpeck MD, Kuczmarski J et al. (2001) Association between infant breastfeeding and overweight in young children. JAMA 285, 2453-2460.

11. Bogen D, Hanusa BH \& Whitaker RC (2004) The effect of breast-feeding with and without formula use on the risk of obesity at 4 years of age. Obes Res 12, 1527-1535.

12. Kalies H, Heinrich J, Borte $M$ et al. (2005) The effect of breastfeeding on weight gain in infants: results of a birth cohort study. Eur J Med Res 10, 36-42.

13. Gillman MW, Rifas-Shiman SL, Kleinman K et al. (2008) Developmental origins of childhood overweight: potential public health impact. Obesity (Silver Spring) 16, 1651-1656.

14. Carvalho R, Johnson E, Kozlosky M et al. (2008) Clinical profile of the overweight child in the new millennium. Clin Pediatr (Phila) 47, 476-482.

15. Dewey KG (2003) Is breastfeeding protective against child obesity? J Hum Lact 19, 9-18.

16. Arenz S, Ruckerl R, Koletzko B et al. (2004) Breast-feeding and childhood obesity - a systematic review. Int I Obes Relat Metab Disord 28, 1247-1256.
17. Kenyan Central Bureau of Statistics, Kenyan Ministry of Health \& ORC Macro (2004) Kenya Demographic and Health Survey 2003. Calverton, MD: CBS, MOH \& ORC Macro.

18. World Health Organization (2007) WHO Anthro for Personal Computers Manual. Software for Assessing Growth and Development of the World's Children. Geneva: WHO.

19. Gorstein J, Sullivan K, Yip R et al. (1994) Issues in the assessment of nutritional status using anthropometry. Bull World Health Organ 72, 273-283.

20. Semproli S \& Gualdi-Russo E (2007) Childhood malnutrition and growth in a rural area of western Kenya. Am J Phys Anthropol 132, 463-469.

21. Birch LL \& Fisher JO (1998) Development of eating behaviors among children and adolescents. Pediatrics 101, 539-549.

22. Perusse L \& Bouchard C (2000) Gene-diet interactions in obesity. Am J Clin Nutr 72, 5 Suppl., 1285S-1290S.

23. Oliveria SA, Ellison RC, Moore LL et al. (1992) Parent-child relationships in nutrient intake: the Framingham Children's Study. Am J Clin Nutr 56, 593-598.

24. Nguyen VT, Larson DE, Johnson RK et al. (1996) Fat intake and adiposity in children of lean and obese parents. $A m \mathrm{~J}$ Clin Nutr 63, 507-513.

25. Fisher JO, Birch LL, Smiciklas-Wright H et al. (2000) Breastfeeding through the first year predicts maternal control in feeding and subsequent toddler energy intakes. J Am Diet Assoc 100, 641-646.

26. Armstrong J, Reilly JJ \& Child Health Information Team (2002) Breast-feeding and lowering the risk of childhood overweight. Lancet 359, 2003-2004.

27. Kleiser C, Rosario AS, Mensink GBM et al. (2009) Potential determinants of obesity among children and adolescents in Germany: results from the cross-sectional KiGGS study. BMC Public Health 9, 46.

28. Dubois L \& Girard M (2006) Early determinants of overweight at 4.5 years in a population-based longitudinal study. Int J Obes (Lond) 30, 610-617.

29. Kruger HS, Margetts BM \& Vorster HH (2004) Evidence for relatively greater subcutaneous fat deposition in stunted girls in the North West Province, South Africa, as compared with non-stunted girls. Nutrition 20, 564-569.

30. Steyn NP, Labadarios D, Maunder E et al. \& Directors of the National Food Consumption Survey (2005) Secondary anthropometric data analysis of the national food consumption survey in South Africa: the double burden. Nutrition 21, 4-13.

31. Hoffman DJ, Sawaya AL, Verreschi I et al. (2000) Why nutritionally stunted children at increased risk of obesity? Studies of metabolic rate and fat oxidation in shantytown children from Sao Paulo, Brazil. Am J Clin Nutr 72, 702-707.

32. Hawkins SS, Cole TJ \& Law C (2008) Maternal employment and early childhood overweight: findings from the UK Millennium Cohort Study. Int J Obes (Lond) 32, 30-38.

33. Fernald LC \& Neufeld LM (2007) Overweight with concurrent stunting in very young children from rural Mexico: prevalence and associated factors. Eur J Clin Nutr 61, 623-632.

34. Martorell R, Khan LK, Hughes ML et al. (2000) Obesity in women from developing countries. Eur J Clin Nutr 54, $247-252$.

35. Christensen DL, Eis J, Hansen AW et al. (2008) Obesity and regional fat distribution in Kenyan populations: impact of ethnicity and urbanization. Ann Hum Biol 35, 232-249.

36. Ong KK, Emmett PM, Noble S et al. (2006) Dietary energy intake at the age of 4 months predicts postnatal weight gain and childhood body mass index. Pediatrics 117, e503-e508.

37. Flynn MAT, McNeil DA, Maloff B et al. (2006) Reducing obesity and related chronic disease risk in children and youth: a synthesis of evidence with 'best practice' recommendation. Obes Rev 7, 7-66. 